материалы, которые производятся отечественными производителями: алкидный органорастворимый и водоэмульсионный полиакрилатный лаки.

Ключевые слова: лакокрасочные материалы; технологические, экологические, экономические критерии; метод анализа иерархий; матрица попарных сравнений; шкала относительной важности объектов Саати.

Olyanyshyn T.V., Yaremchuk L.A. The Use of the Method of Analysis of Hierarchies for the Determination of a Rational Finishing Material according to Basic Production Criteria

The possibility to use mathematical tools for solving production problems related to the rational choice of materials by existing alternatives is studied. The known method of analysis of hierarchies is used for determining the optimum varnish material from three alternatives (alkyd varnish with an organic solvent, poliakrilat water-emulsion varnish and linseed oil modified by rosin) on technological, ecological and economic criteria. The degree of advantage of one criterion above other is performed on the basis of expert estimation, using the scale of relative importance of Saati objects. In-use in-process varnish is widely used by the industrial enterprises for finishing of joiner-build wares (windows, doors, floors). For comparison of the modified linseed oil materials which are produced by domestic producers were chosen the following: alkyd varnish with an organic solvent and water-emulsion poliakrilat varnishes.

Keywords: finishing materials; technological, ecological, and economic criteria; the method of analysis of hierarchies; matrix of pairwise comparisons; the scale of relative importance of Saati objects.

\section{УДК 004.[056+3.75]:061.68}

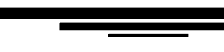

Ст. викл. I.P. Опірський,

ПРОЕКТНЕ МОДЕЛЮВАННЯ КОНФЛІКТУ ЗАГРОЗ

\section{З КОМПЛЕКСНОЮ СИСТЕМОЮ ЗАХИСТУ ІНФОРМАЦІ}

\section{В ІНФОРМАЦІЙНИХ МЕРЕЖАХ ДЕРЖАВИ}

Представлено модель захисту інформації в інформаційній мережі держави 3 повним перекриттям загроз, на основі якої показано механізм захисту, що визначається як ки тія бар'срів, які перекривють одну з областей уразливості комплексної системи

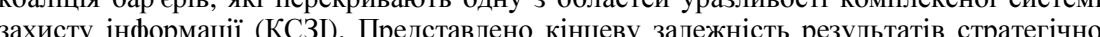
о гри між коаліцією загроз та сукупністю коаліцій комплексноі системи захисту інформаціi у вигляді математичних матриць. На основі теоріп ігор показано, що ефективніст роботи КСЗІ залежить від стійкості бар'єрів і від взаємозв'язків - передаточних функцій, які є зв'язувальним елементом гри, від кількості цих зв'язків напряму залежит ефективність і стійкість роботи КСЗІ.

Ключові слова: несанкціонований доступ, інформаційні мережі держави, комплексні системи захисту інформації, захист інформації, матриця коаліцій, загрози.

Вступ. Глобалізація інформаційних процесів і телекомунікаційних мереж попереджує низку проблем системного характеру, зокрема, інтелектуальної власності, трансакційних відомостей, різноманітного деструктивного впливу на інформацію тощо, серед яких проблема захисту інформації та протидія несанкціонованим діям зловмисників $є$ ключовою $[1,2]$.

В Україні проблема інформаційної безпеки постала вкрай гостро. На сьогодні зусилля Президента України й Ради національної безпеки та оборони України спрямовані на випровадження положень "Доктрини інформаційної безпеки України" [3], оскільки питання про інформаційну безпеку держави та особисто інформаційних мереж держави $є$ найбільш чутливим для системи наці- ональної безпеки і оборони загалом та визначальними для забезпечення національного суверенітету держави зокрема [7].

Функціональна залежність (близько $85 \%$ ) українських стратегічних об'єктів оборонного комплексу та інформаційних структур від закордонних технічних засобів відкриває евентуальному противнику широкі можливості несанкціонованого доступу до інформації, чим становить серйозну загрозу національній безпеці [4]. Тому принциповим аспектом управління національної, регіональної та міжрегіональної безпеки і стратегічної стабільності є системний та комплексний підхід до вирішення проблеми інформаційної безпеки та захисту інформаційних мереж держави (IMД), яка особливо актуальна в сучасних умовах. При цьому умова системності та комплексності $є$ обов'язковою у створенні системи захисту та протидії несанкціонованому доступу (НСД) в ІМД. Вона відповідає вимогам стандартів та документів [5], а також вимогам міжнародних стандартів ISO у сфері інформаційної безпеки [6].

На сьогодні створення комплексної системи захисту інформації (КСЗІ) неможливе без дослідження й узагальнення світового досвіду побудови IМД та їх складових підсистем, ключовим елементом яких є, зокрема, КСЗІ для захисту від НСД. Математичними забезпеченнями таких систем є моделі процесів нападу на інформацію та її захисту і конфлікт загроз, що відбуваються між ними. Базисом таких моделей є математичний аналіз, який не в змозі забезпечити адекватність процесів, що моделюються реальними процесами, які відбуваються в ІМД. Основними причинами недосконалості математичного аналізу, що використовується нині, полягає в труднощах формалізації завдань показу та НСД щодо інформації, загрозами та ії̈ захисту, які пов'язані з процесами, що складно формалізуються і змінюють свої параметри протягом функціонування ІМД, як складової ІМД. Внаслідок цього не виконується вимога до компенсаційного аналізу функціонування КСЗІ, що приводить до зниження їх ефективності та ускладнення розробки перспективних систем на їх базі.

Таким чином, питання про створення та подальшого розвитку підходу до моделювання процесів НСД і визначення конфліктів КСЗІ щодо інформації у ІМД на базі сучасного математичного інструментарію є відкритим і актуальним та потребує детального наукового дослідження.

Об'єкт дослідження - процес конфлікту КСЗІ ІМД з загрозами від НСД.

Предмет дослідження - моделі та методи захисту інформації ІМД від НСД.

Мета роботи - проведення математичного проектного моделювання та аналізу конфлікту коаліції загроз інформаційних мереж держави з сукупністю коаліцій комплексної системи захисту інформації на основі теорії ігр та коаліційної гри.

Виклад основного матеріалу. Моделі захисту інформації є складовими частинами загального процесу моделювання. Моделювання системи полягає у побудові образу системи, адекватної (з точністю до цілей моделювання) системи, яка проектується, і в отриманні за допомогою побудованої моделі потрібних характеристик реальної системи. Таким чином, у загальному випадку, весь процес моделювання можна поділити на дві складові частини:

- побудова моделі;

- реалізація моделі з метою отримання потрібних характеристик системи.

4. Інформашійні технології галузи 
Основне призначення моделей [8] - це створення умов для об'єктивного оцінювання загального стану інформаційної системи з погляду міри уразливості або рівня захищеності інформації в неї. Потреба в таких оцінках, зазвичай, виникає під час аналізу загальної ситуації з метою відпрацювання стратегічних рішень під час організації захисту інформації.

Для формалізації процесу моделювання конфлікту загроз з КСЗІ розглянемо типову модель захисту інформації з повним перекриттям загроз (рис. 1).

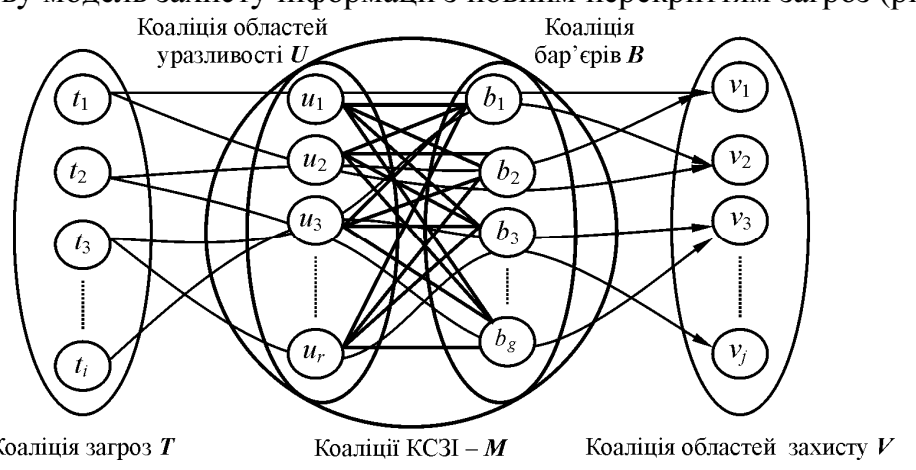

Коаліція загроз Коаліції КСЗІ - $\boldsymbol{M}$ Коаліція областей захисту $V$

Рис. 1. Коаліції, які створюються у моделі захисту інформації з повним перекриттям загро

Ця модель описує прочес взаємодії загроз і ресурсів КСЗІ (бар'єрів та механізмів захисту у складі КСЗІ).

Можна виділити 3 колліиії:

- $T=\left\{t_{i}\right\}-$ коаліція загроз, де $i-$ кількість загроз, за $i=\overline{1, I}$;

- $V=\left\{v_{j}\right\}$ - коаліція ресурсів інформаційної системи, які потрібно захищати, де $j$ - кількість ресурсів, за $j=\overline{1, J}$;

- $M=\left\{m_{k}\right\}-$ коаліція механізмів захисту КСЗІ, де $k-$ кількість механізмів захисту у складі КСЗІ, за $k=\overline{1, K}$;

У механізмах захисту $-m_{k}$, КСЗІ $-M$, мають такі коаліції:

- $U=\left\{u_{r}\right\}$ - області уразливості КСЗІ, де $r$ - кількість місць уразливості, за $r=\overline{1, R}$

- $B=\left\{b_{q}\right\}$ - бар'єри захисту, де $q-$ кількість бар'єрів захисту КСЗІ, за $q=\overline{1, G}$.

У цьому випадку КСЗІ розглядають як сукупність коаліцій

$$
M=\left\{m_{k}\right\}=\{U \times B\} .
$$

Згідно з (1) механізм захисту визначається як коаліція бар'єрів, які перекривають одне з областей уразливості КСЗІ (рис. 2)

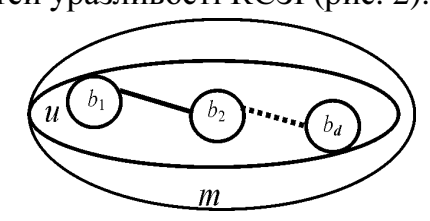

Рис. 2. Механізм захисту КСЗІ, який складається з коаліцій бар'єрів та областей уразливості
З урахуванням наведеного вище можна визначити умови захисту інформації

$$
\forall<t_{i}, v_{i}>\in M \exists\left\{<u_{r}, b_{g}>\mid f\left(t_{i}, v_{j}\right)\right\},
$$

де функціонал $f\left(t_{i}, v_{j}\right)$ - описує виконання умов забезпечення захисту інформації об'єкта $v_{j}$ при наявності загрози $t_{i}$. Таким чином, для КСЗІ з повним перекриттям загроз існують такі бар'єри, які вступають в "гру" (у конфлікт) зі загрозами для інформаційної системи (коаліцій областей захисту).

Наступальну гру коаліцій загроз можна описати аналітично у вигляді функціональних залежностей, які пов'язують характеристики загроз $t_{i} \in T$ та областей захисту $v_{j} \in V$. Кожна з величин $v_{j} \in V$ залежить від $r$-координат областей уразливості і $g$-координат знаходження бар'єрів у механізмах захисту. Ступінь залежності величин $v_{j}$ залежить від векторів координат областей уразливості механізмів захисту $u_{r} \in U$ та бар'єрів $b_{g} \in B$ і визначається передаточними функціями $A_{k g}, C_{k g}, D_{k g}$.

У загальному вигляді наступальну стратегічну гру коаліцій загроз та КСЗІ можна описати виразом у вигляді

$$
V(p)=T(p) \times A_{k g}+U(p) \times C_{k g}+B(p) \times D_{k g},
$$

де: $V(p), T(p), U(p), B(p)$ - матриці коаліцій, які розглядаються в грі, розмірністю $j \times 1$, де $p$ - оператор Лапласа; $A_{k g}, C_{k g}, D_{k g}$ - передаточні матриці взаємовідносин коаліцій, які розглядаються, розмірністю $k \times g$. Матриці коаліцій та передаточних взаємозв'язків між ними мають такий вигляд:

$$
\begin{gathered}
V(p)=\left[\begin{array}{c}
v_{1}(p) \\
v_{2}(p) \\
\vdots \\
v_{j}(p)
\end{array}\right] ; T(p)=\left[\begin{array}{c}
t_{1}(p) \\
t_{2}(p) \\
\vdots \\
t_{j}(p)
\end{array}\right] ; A_{k g}=\left[\begin{array}{cccc}
a_{11} & a_{12} & \ldots & a_{1 k} \\
a_{21} & a_{22} & \ldots & a_{1 k} \\
\ldots & \ldots & \ldots & \ldots \\
a_{g 1} & a_{g 2} & \ldots & a_{g k}
\end{array}\right] ; \quad U(p)=\left[\begin{array}{c}
u_{1}(p) \\
u_{2}(p) \\
\vdots \\
u_{r}(p)
\end{array}\right] ; \\
C_{k g}=\left[\begin{array}{cccc}
c_{11} & c_{12} & \ldots & c_{1 k} \\
c_{21} & c_{22} & \ldots & c_{1 k} \\
\ldots & \ldots & \ldots & \ldots \\
c_{g 1} & c_{g 2} & \ldots & c_{g k}
\end{array}\right] ; B(p)=\left[\begin{array}{c}
b_{1}(p) \\
b_{2}(p) \\
\vdots \\
b_{s}(p)
\end{array}\right] ; D_{k g}=\left[\begin{array}{cccc}
d_{11} & d_{12} & \ldots & d_{1 k} \\
d_{21} & d_{22} & \ldots & d_{1 k} \\
\ldots & \ldots & \ldots & \ldots \\
d_{g 1} & d_{g 2} & \ldots & d_{g k}
\end{array}\right] .
\end{gathered}
$$

Підставляючи вираз (3) у рівняння (4) отримуємо кінцеву залежність результатів стратегічної гри між коаліцією загроз та сукупністю коаліцій КСЗІ

$$
\begin{aligned}
{\left[\begin{array}{c}
v_{1}(p) \\
v_{2}(p) \\
\vdots \\
v_{j}(p)
\end{array}\right]=\left[\begin{array}{c}
t_{1}(p) \\
t_{2}(p) \\
\vdots \\
t_{j}(p)
\end{array}\right] \times } & {\left[\begin{array}{cccc}
a_{11} & a_{12} & \ldots & a_{1 k} \\
a_{21} & a_{22} & \ldots & a_{1 k} \\
\ldots & \ldots & \ldots & \ldots \\
a_{g 1} & a_{g 2} & \ldots & a_{g k}
\end{array}\right]+\left[\begin{array}{c}
u_{1}(p) \\
u_{2}(p) \\
\vdots \\
u_{r}(p)
\end{array}\right] \times\left[\begin{array}{cccc}
c_{11} & c_{12} & \ldots & c_{1 k} \\
c_{21} & c_{22} & \ldots & c_{1 k} \\
\ldots & \ldots & \ldots & \ldots \\
c_{g 1} & c_{g 2} & \ldots & c_{g k}
\end{array}\right] } \\
& +\left[\begin{array}{c}
b_{1}(p) \\
b_{2}(p) \\
\vdots \\
b_{s}(p)
\end{array}\right] \times\left[\begin{array}{cccc}
d_{11} & d_{12} & \ldots & d_{1 k} \\
d_{21} & d_{22} & \ldots & d_{1 k} \\
\ldots & \ldots & \ldots & \ldots \\
d_{g 1} & d_{g 2} & \ldots & d_{g k}
\end{array}\right] .
\end{aligned}
$$


Для доказу виразу (5) можна розглянути рис. 3, на якому представлено приклад умовної гри коаліцій загроз та КСЗІ

Умовно позначимо кількість загроз (причому для розрахунку не будемо їм надавати вагові коефіцієнти. Тільки розподілимо їх на класи: атак - I, відмов - II та аварій - III). У цьому випадку не розглядаємо вагові коефіцієнти можливості впливу загроз на КСЗІ, які в своєї коаліції впливають на КСЗІ

Розглянемо крайні випадки коаліційної гри.

Приклад 1. Потрібно проаналізувати роботу КСЗІ за "відсутності бар'єрів КСЗІ" (бар'єри не затримують загрози). Тобто моделюються шляхи впливу коаліції загроз на коаліцію областей захисту.

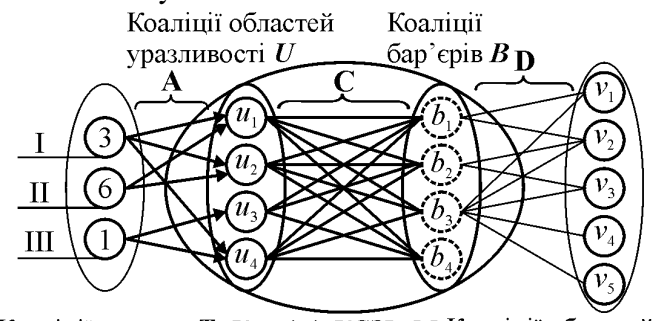

Коаліції загроз - $T$ К Коаліції КСЗІ- $M$ Коаліції областей захисту - $V$

Рис. 3. Стратегічна гра (конфлікт) між коаліціями загроз та КСЗ

Приклад 2. Потрібно проаналізувати роботу КСЗІ за наявності різних за стійкістю бар'ерів захисту КСЗІ. Тоббто потрібно оцінити роботу КСЗІ в умовах нестабільних за стійкістю бар'єрів. При цьому бар'єр $b_{1}$ може пропустити загрозу 3 вірогідністю $P_{b_{1}}=0,2 ;$ бар'єр $b_{2}-$ з вірогідністю $P_{b_{2}}=0,4$; а наступні бар'єри: $P_{b_{3}}=0,1 ; P_{b_{4}}=0,3$.

Приклад 3. Потрібно проаналізувати роботу КСЗІ за наявності стійких бар'ерів захисту (бар'єри повністю блокують загрози). Тобто КСЗІ побудована правильно.

Використовуючи вираз (5), можна отримати графік, який зображено на рис. 4. 3 рис. 4 можна зробити висновок, що ефективність роботи КСЗІ залежить від стійкості бар'єрів. Але надалі потрібно звернути увагу на взаємозв'язки - передаточні функції, які є зв'язувальним елементом цієї гри. Від кількості цих зв'язків напряму залежить ефективність і стійкість роботи КСЗІ

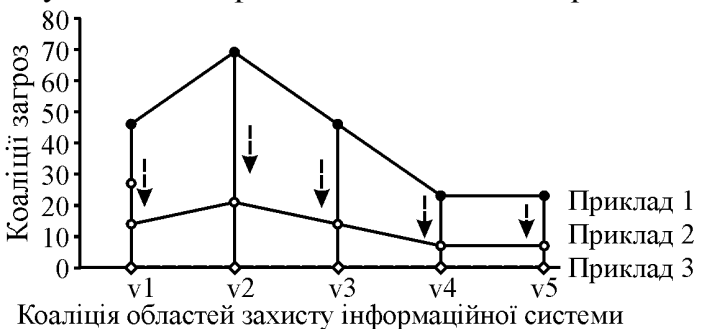

Рис. 4. Ефективність стратегічної гри коаліцій загроз і КСЗІ

Висновки. Розроблення принципово нових математичних моделей процесів захисту від НСД в ІМД природно потрібно здійснювати, виходячи із аналізу відомих підходів і моделей, а також тих принципів, на основі яких вони розроблені і які покладені в їх основу.

Проектне моделювання конфлікту загроз і КСЗІ показало, що ефективність роботи захисту в ІМД залежить від стійкості бар'єрів, проте від кількості передаточних функцій залежить ефективність та стійкість роботи самої системи. Під час проектного моделювання потрібно розраховувати кількісні та якісні попередні показники ефективності захисту інформації системи, яка проектується. Це важливо тому, що закладені на цьому етапі критерії та показники надалі можуть звезти на нуль усю велику роботу, витрати та цінність інформації, які закладаються та відпрацьовуються на усіх етапах створення як інформаційної системи загалом, так і КСЗІ зокрема.

\section{Література}

1. Павлов І.М. Проектування комплексних систем захисту інформашії / І.М. Павлов, В.О. Хорошко. - К. : Вид-во ВІТІ - ДУІКТ, 2011. - 245 с

2. Гайворонський М.В. Безпека інформаційно-комунікаційних систем / М.В. Гайворонський, О.М. Новіков. - К. : Вид-во група ВНV, 2009. - 608 с

3. Голубенко О.Л. Політика інформаційної безпеки / О.Л. Голубенко, В.О. Хорошко, О.С. Петров, С.М. Головань, Ю.С. Яремчук. - Луганськ : Вид-во СНІ ім. В. Даля, 2009. - 300 с. 4. Кобозєва А.А. Аналіз захищеності інформаційних систем / А.А. Кобозєва, І.О. Мачалін, В.О. Хорошко. - К. : Вид-во ДУІКТ, 2010. - 316 с.

5. Малюк А.А. Информационная безопасность: Концептуальные и методические основы защиты информации / А.А. Малюк. - М. : Изд-во "Высш. шк.", 2004. - 280 с.

6. Тимченко А.А. Основы информатики системного проектирования объектов новой техник / А.А. Тимченко, А.А. Радионов. - К. : Изд-во "Наук. думка", 2000. - 152 с

7. Михайлов С.Ф. Информационная безопасность. Защита информации в автоматизированных системах. Основные концепции / С.Ф. Михайлов, В.А. Петров, О.А. Тимофеев. - М. : Изд-во "Связь", 1995. - 56 с

8. Дзюбаль О.П. Теоретичні основи національної безпеки України / О.П. Дзюбань, О.В. Соскін. - К. : Вид-во "Освіта України", 2008. - 384 с

Опирский И.Р. Проектное моделирование конфликта угроз с комплек-

\section{сной системой защиты информации в информационных сетях государства}

Представлена модель защиты информации в информационной сети государства полным перекрытием угроз, на основе которой показан механизм защиты, который определяется как коалиция барьеров, которые перекрывают одну из областей уязвимости комплексной системы защиты информации (КСЗИ). Представлена конечная зависимость результатов стратегической игры между коалицией угроз и совокупностью коалиций комплексной системы зашиты информации в виде математических матрищ. Н основе теории игр показано, что эффективность работы КСЗИ зависит от устойчивости основе тов с тойчивость работы КСЗИ.

Ключевые слова: несанкционированный доступ, информационные сети государства, комплексные системы защиты информации, защита информации, матрица коалиций, угрозы.

Opirskyy I.R. Project Simulation of Conflict Threats with Comprehensive

\section{Protection of Information in State Information Networks}

The model of information security in the state information network with full overlapping threats is presented. Based on this model, a protection mechanism shows that the coalition is defined as barriers that block one of the areas of vulnerability of complex information protection system (CIPS). Some final results of dependence between the coalition strategy game set of threats and coalitions comprehensive information security system as a mathematical matrix are presented. Based on game theory it is shown that the effectiveness of the CIPS depends on the stability of barriers and relationships - transfer function, which is the binding elemer. game, the number of these connections depends in efficiency and stability of the CIPS

Keywords: unauthorized access to information networks of state, integrated systems of information protection, information security, coalitions matrix, threat. 